\title{
Krasnosel'skii-Mann-Opial type iterative solution of $m$-accretive operator equation and its stability in arbitrary Banach spaces
}

Yuguang $X u^{1}$, Zeqin Liu² and Zuhua Liu' ${ }^{1,3^{*}}$

"Correspondence:

liuzuhua@hotmail.com

'Department of Mathematics,

Kunming University, Kunming,

Yunnan 650214, P.R. China

${ }^{3}$ Department of "Francesco

Brioschi" Mathematics, Milano

University of Science and

Technology, Milan, 20133, Italy

Full list of author information is

available at the end of the article

\begin{abstract}
Let $X$ be a Banach space. Suppose that $A: X \rightarrow X$ is a Lipschitz accretive operator. The objective of this note is to discuss simultaneously the existence and uniqueness of solution of the equation $x+A x=f$ for any given $f \in X$, and its convergence, estimate of convergent rate, and stability of Krasnosel'skiil-Mann-Opial type iterative solution $\left\{x_{n}\right\} \subseteq X$. If an iterative parameter is selected suitably then the iterative procedure converges strongly to a unique solution of the equation and the iterative process is stable in arbitrary Banach space without any convexity or reflexivity. In particular, if $A$ is nonexpansive then an estimate of the convergence rate can be written as $\left\|x_{n+1}-q\right\| \leq\left(\frac{17}{18}\right)^{n+1}\left\|x_{0}-q\right\|$ where $q \in X$ is a solution of $x+A X=f$.

MSC: $47 \mathrm{H} 06 ; 47 \mathrm{H} 10 ; 47 \mathrm{H} 17$
\end{abstract}

Keywords: accretive operator; $m$-accretive operator; iterative solution; stability; Krasnosel'skiî-Mann-Opial type iterative procedure

\section{Introduction and preliminaries}

Throughout this paper, $X$ is assumed to be a real Banach space.

An operator $A$ with domain $D(A) \subset X$ and range $R(A) \subset X$ is said to be accretive if and only if we have the inequality

$$
\|x-y\| \leq\|x-y+r(A x-A y)\|
$$

for all $x, y \in D(A)$ and $r>0$. An accretive operator $A$ is said to be $m$-accretive if $R(I+\lambda A)=$ $X$ for all (or, equivalently, for some) $\lambda>0$, where $I$ stands for the identity operator on $X$.

The notion of accretive operators was introduced and studied independently by Browder [1] and Kato [2]. The interest and importance of accretive operators stems mainly from the fact that many physically significant problems can be modeled in terms of an initial value problem of the form

$$
\frac{d x(t)}{d t}+A x(t)=0, \quad x(0)=x_{0}
$$

Here $A$ is an accretive operator in a Hilbert space or an appropriate Banach space. Typical examples where such evolution equations occur can be found in the heat, wave or Schrödinger equation. One of the earliest problems in the theory of accretive operators

C2014 Xu et al.; licensee Springer. This is an Open Access article distributed under the terms of the Creative Commons Attribution License (http://creativecommons.org/licenses/by/2.0), which permits unrestricted use, distribution, and reproduction in any medium, provided the original work is properly cited. 
was to solve (1.2). A fundamental result in the theory, due to Browder [1], states that the initial value problem (1.2) is solvable if $A$ is locally Lipschitzian and accretive on $H$ (a Hilbert space). In particular, if $A$ is $m$-accretive then the equation

$$
x+A x=f \quad x \in X
$$

has a solution for any given $f \in X$. Martin [3] extended the results, that is, he proved that (1.2) is solvable if $A$ is continuous and accretive on $X$. Furthermore, if $A$ is continuous and accretive then $A$ must be $m$-accretive. It implies that (1.3) has a solution $q \in X$ for any given $f \in X$. If $q^{*}$ also is a solution of (1.3), then we have the inequality

$$
\left\|q-q^{*}\right\| \leq\left\|q-q^{*}+r\left(A q-A q^{*}\right)\right\|=|1-r|\left\|q-q^{*}\right\|
$$

for all $r>0$. To pick $r=1$, we have $q=q^{*}$. It follows that for the equation $x+A x=f$ there exists a unique solution $q \in X$.

It is well known that the approximative solution of operator equation is closely related with the iterative sequence convergence of a fixed point of the mapping. Therefore a brief history on iterative methods is reviewed in the following.

In 1922, using the Picard iterative method, Banach's fixed point theorem was obtained where $S: D(S) \subseteq X \rightarrow X$ is a contractive type operator. For a given nonexpansive mapping $S$ of a closed convex set $C$ of a Banach space $X$ into itself and $\lambda \in(0,1)$, the operator $S_{\lambda}=$ $\lambda I+(1-\lambda) S$ also is nonexpansive. Moreover, as has been pointed out by Krasnosel'skii [4] for $\lambda=1 / 2$ and by Schaefer [5] for an arbitrary $\lambda$, if $X$ is uniformly convex and $S$ has at least one fixed point in $C$, then the operator $S_{\lambda}$ is asymptotically regular. For any $x_{0} \in C$ and any $\lambda \in(0,1)$, Opial proved that the iterative sequence $\left\{S_{\lambda}^{n+1} x_{0}\right\}$ (or $\left.\left\{\lambda x_{n}+(1-\lambda) S x_{n}\right\}\right)$ is weakly convergent to a fixed point of $S$ under some assumptions (see, e.g., Theorem 3 of [6]).

On the other hand, the so-called general Mann [7] iterates $\left\{x_{n}\right\}_{n \geq 0}$ of the mapping $S$ are defined by

$$
x_{0} \in X, \quad x_{n+1}=S\left(v_{n}\right), \quad v_{n}=\sum_{k=0}^{\infty} a_{n k} x_{k}, \quad n \geq 0 .
$$

Here $\left(a_{n j}\right)=A$ is an infinite real matrix under some conditions. Most of the literature deals with the specialized Mann iteration method defined by

$$
\left\{\begin{array}{l}
x_{0} \in C, \\
x_{n+1}=\left(1-\alpha_{n}\right) x_{n}+\alpha_{n} S x_{n}, \quad n \geq 0,
\end{array}\right.
$$

where $C$ is a closed convex subset of $X$ and $\left\{\alpha_{n}\right\}$ is a real sequence satisfying the following conditions:

$$
\text { (i) } \alpha_{0}=1, \quad \text { (ii) } 0<\alpha_{n}<1, \quad n \geq 1, \quad \text { (iii) } \sum_{n=0}^{\infty} \alpha_{n}=\infty
$$

In this note, we need an iterative method, the so-called Krasnosel'skiî-Mann-Opial type iterative procedure which is defined as follows. 
Definition 1.1 For any given $x_{0} \in X$, the iterative sequence $\left\{x_{n}\right\}$ is defined by

$$
x_{n+1}=(1-\alpha) x_{n}+\alpha S x_{n}, \quad n \geq 0,
$$

where the iterative parameter $\alpha \in(0,1)$.

In 1986, Chidume [8, 9] proved that the Mann iterative sequence converges strongly to a solution of the equation $x+A x=f$ where $A$ is a Lipschitz accretive operator defined on the Hilbert space $H$ or the space $L_{p}$. The result was generalized by Ding and Deng [10], that is, they proved that the Ishikawa iterative sequence converges strongly to a solution of the equation $x+A x=f$ where $A$ is a Lipschitz accretive operator defined on $p$-uniformly smooth Banach space $X$. Zhu [11] proved that the Mann iterative sequence converges strongly to the unique solution of the equation $x+A x=f$ under slightly different conditions where $A: D(A) \subseteq X \rightarrow X$ is a Lipschitz $m$-accretive operator and $D(A)$ is an open subset of a uniformly smooth Banach space $X$. Recently, Chidume and Osilike further extended the above results to the Mann iterative sequence (see, e.g., Theorem 5 of [12]), where $A$ is Lipschitz $m$-accretive and $D(A)$ is a closed subset of a real Banach space $X$ which is both uniformly convex and $p$-uniformly smooth.

The objective of this note is to discuss simultaneously the existence and uniqueness of a solution of the equation $x+A x=f$ for any given $f \in X$, and its convergence, estimate of convergent rate, and stability of a Krasnosel'skii-Mann-Opial type iterative solution. If the iterative parameter is selected suitably then the iterative procedure converges strongly to a unique solution of the equation and the iterative process is stable in arbitrary Banach space without any convexity or reflexivity.

Remark 1.2 A class of operators closely related to the class of accretive operators is the class of dissipative operators. An operator $S: D(A) \subseteq X \rightarrow X$ is said to be dissipative if and only if $(-S)$ is accretive and $S$ is called $m$-dissipative if $(-S)$ is $m$-accretive (see, e.g., Barbu [13]). Some related results of the equation $x-\lambda T x=f$ are also proved in $[9,10,14]$ where $\lambda>0$ and $T$ is a Lipschitzian dissipative operator on $X$.

To set the framework we recall some basic notations as follows.

Definition 1.3 [15] Let $S: X \rightarrow X$ be an operator. Suppose that the iterative sequence $\left\{x_{n}\right\}_{n=0}^{\infty} \subset X$ defined by $x_{n+1}=f\left(S, x_{n}\right)$, and $\left\{x_{n}\right\}$ converges strongly to $q \in F(S)=\{x \in X$ : $S x=x\} \neq \emptyset$. Furthermore, suppose that $\left\{\epsilon_{n}\right\}$ is a sequence in $(0, \infty)$ given by $\epsilon_{n}=\| z_{n+1}-$ $f\left(S, z_{n}\right) \|$ where $\left\{z_{n}\right\}_{n=0}^{\infty}$ is arbitrary sequence in $X$. Then the iteration procedure $\left\{x_{n}\right\}$ is said to be stable with respect to $S$ (or, simply, $S$-stable) if $\lim _{n \rightarrow \infty} \epsilon_{n}=0$ implies that $\lim _{n \rightarrow \infty} z_{n}=q$.

Lemma 1.4 [16] Let $\left\{a_{n}\right\}$ be a nonnegative real sequence and $\left\{\delta_{n}\right\}$ be a real sequence in $[0,1]$ such $\sum_{n=0}^{\infty} \delta_{n}=\infty$. If there exists a positive integer $n_{1}$ such that

$$
a_{n+1} \leq\left(1-\delta_{n}\right) a_{n}+\delta_{n} \epsilon_{n} \quad \forall n \geq n_{1}
$$

where $\epsilon_{n} \geq 0$ for all $n \geq 0$ and $\epsilon_{n} \rightarrow 0($ as $n \rightarrow \infty)$, then we have $\lim _{n \rightarrow \infty} a_{n}=0$. 


\section{Iterative solution of $\boldsymbol{m}$-accretive operator equation and its stability}

We now prove the following propositions.

Proposition 2.1 If $A: X \rightarrow X$ is a Lipschitz accretive operator with Lipschitz constant $L$ $(1 \leq L)$, then the sequence $\left\{x_{n}\right\}$ is defined by $(1.8)$ is an iterative solution of $(1.3)$, where the iterative parameter $\alpha_{0} \in\left(0,1 /(L+1)^{2}\right)$.

Proof Since $A$ is a continuous accretive operator, the equation $x+A x=f$ has a solution $q \in X$. Setting $S: X \rightarrow X$ by $S x=f-A x$, we have two facts: first, $q$ is a solution of $x+A x=f$ if and only if $q$ is a fixed point of $S$. It implies that $S$ is a dissipative operator; next, it is easy to see that $L$ also is a Lipschitz constant of $S$. In fact, we have

$$
\|S x-S y\|=\|A y-A x\| \leq L\|x-y\|
$$

for all $x, y \in X$. Also, (1.8) can be written as

$$
\left\{\begin{array}{l}
x_{0} \in X, \\
x_{n+1}=(1-\alpha) x_{n}+\alpha S x_{n}
\end{array} \quad(n \geq 0) .\right.
$$

From (1.1), we obtain

$$
\|x-y\| \leq\|x-y-r(S x-S y)\|
$$

for all $x, y \in X$ and $r>0$. For any given $x_{0} \in X$, utilizing (2.2) and (2.3), we have

$$
\begin{aligned}
& \begin{array}{l}
(1+\alpha)\left[\left(x_{n+1}-q\right)-\alpha(1+\alpha)^{-1}\left(S x_{n+1}-q\right)\right] \\
\quad= \\
\quad\left(1-\alpha^{2}\right)\left(x_{n}-q\right)+\alpha(1+\alpha)\left(S x_{n}-q\right)-\alpha\left(S x_{n+1}-q\right) \\
\quad=\left(x_{n}-q\right)+\alpha^{2}\left(S x_{n}-x_{n}\right)+\alpha\left(S x_{n}-S x_{n+1}\right),
\end{array} \\
& \left\|S x_{n}-x_{n}\right\| \leq\left\|x_{n}-q\right\|+\left\|S x_{n}-q\right\| \leq(L+1)\left\|x_{n}-q\right\|
\end{aligned}
$$

and

$$
\left\|S x_{n}-S x_{n+1}\right\| \leq \alpha L\left\|S x_{n}-x_{n}\right\| \leq \alpha L(L+1)\left\|x_{n}-q\right\|
$$

for any $n \geq 0$. Putting $r=\alpha /(1+\alpha)$ in (2.3), it follows from (2.2), (2.4), (2.5), and (2.6) that

$$
\begin{aligned}
(1+\alpha)\left\|x_{n+1}-q\right\| & \leq(1+\alpha)\left\|x_{n+1}-q-\alpha(1+\alpha)^{-1}\left(S x_{n+1}-q\right)\right\| \\
& =\left\|x_{n}-q+\alpha^{2}\left(S x_{n}-x_{n}\right)+\alpha\left(S x_{n}-S x_{n+1}\right)\right\| \\
& \leq\left\|x_{n}-q\right\|+\alpha^{2}\left\|S x_{n}-x_{n}\right\|+\alpha\left\|S x_{n}-S x_{n+1}\right\| \\
& \leq\left(1+\alpha^{2}\right)\left\|x_{n}-q\right\|+\alpha^{2} L(L+2)\left\|x_{n}-q\right\| \\
& =\left[1+(L+1)^{2} \alpha^{2}\right]\left\|x_{n}-q\right\|
\end{aligned}
$$

for all $n \geq 0$. Thus (2.7) can be written as

$$
\left\|x_{n+1}-q\right\| \leq \frac{1+(L+1)^{2} \alpha^{2}}{1+\alpha}\left\|x_{n}-q\right\| .
$$


Putting

$$
Q(\alpha)=\frac{1+(L+1)^{2} \alpha^{2}}{1+\alpha}<1
$$

we obtain $\alpha<\frac{1}{(L+1)^{2}}$. Thus, (2.9) can be written as

$$
\left\|x_{n+1}-q\right\| \leq Q(\alpha)\left\|x_{n}-q\right\| \leq[Q(\alpha)]^{n+1}\left\|x_{0}-q\right\| .
$$

It implies that $\left\{x_{n}\right\}$ converges strong to $q$ if $\alpha<\frac{1}{(L+1)^{2}}$, i.e. $\left\{x_{n}\right\}$ is an iterative solution of (1.3) and

$$
\lim _{n \rightarrow+\infty}\left\|x_{n}-q\right\|=0
$$

This completes the proof.

Remark 2.2 In Proposition 2.1, there exists an $\alpha^{*} \in\left(0,1 /(L+1)^{2}\right)$ such that the convergent rate is fastest in (2.10). In fact, it follows from

$$
Q(\alpha)=\frac{1+(L+1)^{2} \alpha^{2}}{1+\alpha}
$$

that

$$
\alpha^{*}=\frac{\sqrt{L^{2}+2 L+2}-L-1}{L+1},
$$

and

$$
Q\left(\alpha^{*}\right)=2(L+1)\left(\sqrt{L^{2}+2 L+2}-L-1\right) .
$$

For the operation in the computer, we need to select an $\alpha_{0} \in\left(0,1 /(L+1)^{2}\right)$. Since

$$
\alpha^{*}=\frac{1}{(L+1)\left(\sqrt{(L+1)^{2}+1}+L+1\right)}<\frac{1}{2(L+1)^{2}}<\frac{1}{(L+1)^{2}},
$$

we take $\alpha_{0}=\frac{1}{2(L+1)^{2}}$ so that the estimation of convergent rate of $\left\{x_{n}\right\}$ can be written as

$$
\left\|x_{n+1}-q\right\| \leq\left[Q\left(\alpha_{0}\right)\right]^{n+1}\left\|x_{0}-q\right\|=\left(\frac{4 L^{2}+8 L+5}{4 L^{2}+8 L+6}\right)^{n+1}\left\|x_{0}-q\right\|
$$

for any $n \geq 0$.

Example 2.3 If operator $A$ is nonexpansive then $L=1$. Thus, (2.16) can be written as

$$
\left\|x_{n+1}-q\right\| \leq\left(\frac{17}{18}\right)^{n+1}\left\|x_{0}-q\right\|
$$

for all $n \geq 0$. 
In the sequel, we need to discuss the stability of the iterative solution of (1.3).

Proposition 2.4 If the conditions of Proposition 2.1 are satisfied then the Krasnosel'skilMann-Opial type iterative solution $\left\{x_{n}\right\}$ of $(1.3)$ is S-stable.

Proof Let $\left\{z_{n}\right\}$ is any sequence in $X$. Setting

$$
p_{n}=(1-\alpha) z_{n}+\alpha S z_{n} \quad(n \geq 0)
$$

we have

$$
\begin{aligned}
\left\|p_{n}-q\right\| & =\left\|p_{n}-q-\alpha(1+\alpha)^{-1}\left(S p_{n}-S q\right)\right\| \\
& =(1+\alpha)^{-1}\left\|(1+\alpha)\left(p_{n}-q\right)-\alpha\left(S p_{n}-q\right)\right\| \\
& \leq(1+\alpha)^{-1}\left(\left\|z_{n}-q\right\|+\alpha^{2}\left\|S z_{n}-z_{n}\right\|+\alpha\left\|S z_{n}-S p_{n}\right\|\right) \\
& \leq(1+\alpha)^{-1}\left[1+(L+1) \alpha^{2}+L(L+1) \alpha^{2}\right]\left\|z_{n}-q\right\| \\
& =(1+\alpha)^{-1}\left[1+(L+1)^{2} \alpha^{2}\right]\left\|z_{n}-q\right\|
\end{aligned}
$$

for all $n \geq 0$. To take

$$
\alpha=\frac{1}{2(L+1)^{2}},
$$

we have

$$
\left\|z_{n+1}-q\right\| \leq\left\|z_{n+1}-p_{n}\right\|+\left\|p_{n}-q\right\|=\epsilon_{n}+\frac{4 L^{2}+8 L+5}{4 L^{2}+8 L+6}\left\|z_{n}-q\right\|
$$

and

$$
\epsilon_{n}=\left\|z_{n+1}-p_{n}\right\| \leq\left\|z_{n+1}-q\right\|+\left\|p_{n}-q\right\| \leq\left\|z_{n+1}-q\right\|+\frac{4 L^{2}+8 L+5}{4 L^{2}+8 L+6}\left\|z_{n}-q\right\| .
$$

It follows from the Lemma 1.4, (2.21), and (2.22) that

$$
\lim _{n \rightarrow \infty} z_{n}=q \Leftrightarrow \lim _{n \rightarrow \infty} \epsilon_{n}=0 .
$$

That is, the Krasnosel'skiî-Mann-Opial type iterative solution is $S$-stable.

This completes the proof.

Remark 2.5 The corresponding results (see, for example, Theorem 1 of [17], Theorem 1 of [18] and Theorem 3.5 of [19]) are improved in the following senses:

(1) For the Krasnosel'skiî-Mann-Opial type iterative solution of $x+A x=f$, we study simultaneously the existence, uniqueness, convergence, convergence rate estimate, and the stability.

(2) The operator may not be strongly accretive, $\phi$-strongly accretive or uniformly accretive. The cases that $A$ is uniformly accretive, $\phi$-strongly accretive or strongly accretive, as regards (1.2) and (1.3), have been studied in [17, 19-21] and [22, 23]; 
(3) By the way, the iterative parameter $\alpha$ does not depend on any geometric structure of space $X$ and on any properties of the operators, but the selection of the parameter is to deal with the convergent rate of the iterative sequence. In this paper, a prototype of the iteration parameter is

$$
\alpha=\frac{1}{2(L+1)^{2}}
$$

It is convenient in simplifying the computation and obtaining the convergent acceleration.

\author{
Competing interests \\ The authors declare that they have no competing interests.
}

\title{
Authors' contributions
}

All authors contributed equally and significantly to this research work. All authors read and approved the final manuscript.

\section{Author details}

${ }^{1}$ Department of Mathematics, Kunming University, Kunming, Yunnan 650214, P.R. China. ${ }^{2}$ Department of Mathematics, Liaoning Normal University, Dalian, Liaoning 116029, P.R. China. ${ }^{3}$ Department of "Francesco Brioschi" Mathematics, Milano University of Science and Technology, Milan, 20133, Italy.

\section{Acknowledgements}

The authors would like to thank the referees for his/her invaluable comments and suggestions, which improved this work significantly.

Received: 20 August 2013 Accepted: 31 January 2014 Published: 14 Feb 2014

\section{References}

1. Browder, FE: Nonlinear mappings of nonexpansive and accretive type in Banach spaces. Bull. Am. Math. Soc. 73, 875-882 (1967)

2. Kato, T: Nonlinear semigroups and evolution equations. J. Math. Soc. Jpn. 19, 508-520 (1967)

3. Martin, RH Jr.: A global existence theorem for autonomous differential equations in Banach spaces. Proc. Am. Math. Soc. 26, 307-314 (1970)

4. Krasnosel'skiĭ, MA: Two observations about the method of successive approximations. Usp. Mat. Nauk 10, 123-127 (1955)

5. Schaefer, H: Über die methode sukzessiver approximationen. Jahresber. Dtsch. Math.-Ver. 59, 131-140 (1957)

6. Opial, Z: Weak convergence of successive approximations for nonexpansive mappings. Bull. Am. Math. Soc. 73, 591-5597 (1967)

7. Mann, WR: Mean value methods in iteration. Proc. Am. Math. Soc. 4, 506-510 (1953)

8. Chidume, CE: An approximation method for monotone Lipschitzian operators in Hilbert space. J. Aust. Math. Soc. 41 59-63 (1986)

9. Chidume, CE: Iterative solution of nonlinear equations of the monotone and dissipative types. Appl. Anal. 33, 79-86 (1989)

10. Ding, XP, Deng, L: Iterative solution of nonlinear equations of the monotone and dissipative types in uniformly smooth Banach spaces. J. Sichuan Normal Univ. 17, 43-48 (1994)

11. Zhu, L: Iterative solution of nonlinear equations involving $m$-accretive operators in Banach spaces. J. Math. Anal. Appl. $188,410-415$ (1994)

12. Chidume, CE, Osilike, MO: Approximation methods for nonlinear operator equations of the $m$-accretive type. J. Math. Anal. Appl. 189, 225-239 (1995)

13. Barbu, V: Nonlinear Semigroups and Differential Equations in Banach Spaces. Noordhoff, Leyden (1976)

14. Ding, XP: Iterative process with errors of nonlinear equations involving $m$-accretive operators. J. Math. Anal. Appl. 209, 191-201 (1997)

15. Chang, SS, Cho, Y, Zhou, H: Iterative Methods for Nonlinear Operator Equations in Banach Spaces. Nova Science Publishers, Hauppauge (2002)

16. Reich, S: Constructive techniques for accretive and monotone operators. In: Applied Nonlinear Analysis, pp. $335-345$. Academic Press, New York (1979)

17. Liu, LW: Strong convergence of iteration methods for equations involving accretive operators in Banach spaces. Nonlinear Anal. 42, 271-276 (2000)

18. Zeng, LC: On the convergence rate estimates of iteration methods for equations involving accretive operators in Banach spaces. Math. Appl. 15(2), 80-84 (2002)

19. Liu, ZQ, Xu, YG, Kang, SM: Almost stable iteration schemes for local strongly pseudocontractive and local strongly accretive operators in real uniformly smooth Banach spaces. Acta Math. Univ. Comen. 77, 285-298 (2008)

20. Liu, ZQ, Xu, YG, Cho, YJ: Iteration solution of nonlinear equations with $\phi$-strongly accretive operators. Arch. Math. 77, 508-516 (2001)

21. Liu, ZQ, Kang, SM: Convergence theorems for $\phi$-strongly accretive and $\phi$-hemicontractive operators. J. Math. Anal. Appl. 253, 35-49 (2001) 
22. Osilike, MO: Iterative solutions of nonlinear $\phi$-strongly accretive operator equations in arbitrary Banach spaces. Nonlinear Anal. 36, 1-9 (1999)

23. Osilike, MO: Iterative solution of nonlinear equations of the $\phi$-strongly accretive type. J. Math. Anal. Appl. 200 259-271 (1996)

10.1186/1687-1812-2014-41

Cite this article as: Xu et al.: Krasnosel'skiï-Mann-Opial type iterative solution of $m$-accretive operator equation and its stability in arbitrary Banach spaces. Fixed Point Theory and Applications 2014, 2014:41

Submit your manuscript to a SpringerOpen ${ }^{\odot}$ journal and benefit from:

- Convenient online submission

- Rigorous peer review

Immediate publication on acceptance

Open access: articles freely available online

- High visibility within the field

- Retaining the copyright to your article

Submit your next manuscript at $>$ springeropen.com 